\title{
Optimization of caseinate-coated simvastatin-zein nanoparticles: improved bioavailability and modified release characteristics
}

This article was published in the following Dove Press journal:

Drug Design, Development and Therapy

23 January 2015

Number of times this article has been viewed

\author{
Osama AA Ahmed ${ }^{1,2}$ \\ Khaled M Hosny ${ }^{1,3}$ \\ Majid M Al-Sawahli',4 \\ Usama A Fahmy' \\ 'Department of Pharmaceutics \\ and Industrial Pharmacy, Faculty \\ of Pharmacy, King Abdulaziz \\ University, Jeddah, Saudi Arabia; \\ ${ }^{2}$ Department of Pharmaceutics \\ and Industrial Pharmacy, Faculty \\ of Pharmacy, Minia University, Minia, \\ Egypt; ${ }^{3}$ Department of Pharmaceutics \\ and Industrial Pharmacy, Faculty \\ of Pharmacy, Beni Suef University, \\ Beni Suef, Egypt; ${ }^{4}$ Holding Company \\ for Biological Products \& Vaccines \\ (VACSERA), Cairo, Egypt
}

\begin{abstract}
The current study focuses on utilization of the natural biocompatible polymer zein to formulate simvastatin (SMV) nanoparticles coated with caseinate, to improve solubility and hence bioavailability, and in addition, to modify SMV-release characteristics. This formulation can be utilized for oral or possible depot parenteral applications. Fifteen formulations were prepared by liquid-liquid phase separation method, according to the Box-Behnken design, to optimize formulation variables. Sodium caseinate was used as an electrosteric stabilizer. The factors studied were: percentage of SMV in the SMV-zein mixture $\left(\mathrm{X}_{1}\right)$, ethanol concentration $\left(\mathrm{X}_{2}\right)$, and caseinate concentration $\left(\mathrm{X}_{3}\right)$. The selected dependent variables were mean particle size $\left(\mathrm{Y}_{1}\right)$, SMV encapsulation efficiency $\left(\mathrm{Y}_{2}\right)$, and cumulative percentage of drug permeated after 1 hour $\left(\mathrm{Y}_{3}\right)$. The diffusion of SMV from the prepared nanoparticles specified by the design was carried out using an automated Franz diffusion cell apparatus. The optimized SMV-zein formula was investigated for in vivo pharmacokinetic parameters compared with an oral SMV suspension. The optimized nanosized SMV-zein formula showed a $131 \mathrm{~nm}$ mean particle size and $89 \%$ encapsulation efficiency. In vitro permeation studies displayed delayed permeation characteristics, with about $42 \%$ and $85 \%$ of SMV cumulative amount released after 12 and 48 hours, respectively. Bioavailability estimation in rats revealed an augmentation in SMV bioavailability from the optimized SMV-zein formulation, by fourfold relative to SMV suspension. Formulation of caseinate-coated SMV-zein nanoparticles improves the pharmacokinetic profile and bioavailability of SMV. Accordingly, improved hypolipidemic activities for longer duration could be achieved. In addition, the reduced dosage rate of SMVzein nanoparticles improves patient tolerability and compliance.
\end{abstract}

Keywords: Box-Behnken design, simvastatin, zein, sodium caseinate

\section{Introduction}

Many promising antihyperlipidemic agents have disadvantageous physicochemical properties that lead to poor bioavailability. ${ }^{1}$ One basic requirement for the successful use of any drug is that it should have sufficient bioavailability to achieve effective therapy at low doses, to minimize the side effects after oral administration. ${ }^{2}$ So it is essential that the drug should be adequately and consistently absorbed. Dyslipidemia, a disorder in lipoprotein metabolism, is one of the key risk factors for cardiovascular diseases. Researchers showed that effective treatment of dyslipidemia reduces the rate of morbidity and mortality. ${ }^{3-5}$

Simvastatin (SMV) is an antihyperlipidemic drug (statin). Previous studies showed that statins have possible anti-inflammatory characteristics unrelated to their lipid-lowering activity. ${ }^{6,7}$ Therefore, statins may have a potential effect in a broad range of inflammatory conditions. SMV is a Class II (according to the
Correspondence: Osama AA Ahmed Department of Pharmaceutics and Industrial Pharmacy, Faculty of Pharmacy, King Abdulaziz University, PO Box 80200, Jeddah, 21589 ,

Saudi Arabia

Email oaahmed@kau.edu.sa
Drug Design, Development and Therapy 2015:9 655-662

Dovepress

http://dx.doi.org// 0.2147/DDDT.S76194 (c) (i) (5) 2015 Ahmed et al. This work is published by Dove Medical Press Limited, and licensed under Creative Commons Attribution - Non Commercial (unported, v3.0) BY LC License. The full terms of the License are available at http://creativecommons.org/licenses/by-nc/3.0/. Non-commercial uses of the work are permitted without any further permission from Dove Medical Press Limited, provided the work is properly attributed. Permissions beyond the scope of the License are administered by Dove Medical Press Limited. Information on
how to request permission may be found at: http://www.dovepress.com/permissions.php 
Biopharmaceutics Classification System [BCS]) drug showing poor bioavailability $(<5 \%)$ related to its limited dissolution rate and to first pass metabolism. ${ }^{8,9}$ Improvement in SMV solubility is essential to improve its low oral bioavailability. ${ }^{10}$

The development of novel oral delivery systems that allow improved dissolution rates for highly lipophilic drugs has drawn the attention of research teams globally. ${ }^{11}$ Nanoparticulate delivery systems have been studied for improving oral bioavailability. ${ }^{12,13}$ Zein, a maize prolamin protein, comprises a group of alcohol-soluble components but is water insoluble. ${ }^{14,15}$ The insoluble characteristic of zein makes it a good candidate for the development of biopolymeric nanoscale particles. ${ }^{16}$ Previous studies investigated the use of zein microparticles for drug delivery. ${ }^{14,16,17}$ However, there are limited reported drug delivery studies of the use of zein nanoparticles. ${ }^{18,19}$ In addition, zein-chitosan and zein-caseinate nanoparticles have been reported for oral delivery. ${ }^{18}$ Like other nanoparticles formulations, the key factor for improving the oral performance of drugs when incorporated into zein nanoparticles is a reduction in particle size. The decrease in particle size results in increase in surface area and saturation solubility, which in turn, improves release rate of the drug and provides high concentration in the gastrointestinal tract (GIT). ${ }^{19}$ Zein nanoparticles usually suffer from impaired redispersion after freeze drying. ${ }^{17}$ Recently, sodium caseinate was used as electrosteric stabilizer for zein nanoparticles. ${ }^{20}$ Sodium caseinate is a milk protein consisting of several soluble caseinates ( $\alpha_{s} 1, \alpha_{s} 2$, $\beta$, and $\kappa) .{ }^{21}$ It has been widely used in food industry as a nutritional ingredient and as a functional component, serving as emulsifier and stabilizer. ${ }^{22}$

The present study aimed to apply pharmaceutical nanotechnology to improve the dissolution rate and to modify the release characteristics of the poorly water soluble drug SMV. The technology involved size reduction in the nanorange, utilizing zein protein coated with sodium caseinate as an electrosteric stabilizer. In addition, optimization activities aimed to understand the experimental parameters affecting the preparation - formulations were optimized and characterized in order to enhance the solubility and bioavailability of SMV.

\section{Materials and methods}

\section{Materials}

SMV was kindly supplied from SAJA Pharmaceutical Company (Jeddah, Saudi Arabia). Zein, sodium caseinate, and all other chemicals were obtained from Sigma-Aldrich Corp (St Louis, MO, USA).

\section{Methodology}

\section{Formulation of caseinate-coated SMV zein} nanoparticles

Box-Behnken experimental design was constructed in this study, using Statgraphics Plus statistical software (version 4; Manugistics Inc., Rockville, MD, USA). The factors studied were: percentage of SMV in the SMV-zein mixture $\left(\mathrm{X}_{1}\right)$, ethanol concentration $\left(\mathrm{X}_{2}\right)$, and caseinate concentration $\left(\mathrm{X}_{3}\right)$. Preliminary studies also provided establishment of the levels for each formulation variable. In addition, the Box-Behnken design was appropriate to study the quadratic response surfaces and to construct second-order polynomial models. The selected dependent variables were mean particle size $\left(\mathrm{Y}_{1}\right)$, SMV encapsulation efficiency $\left(\mathrm{Y}_{2}\right)$, and cumulative percentage of drug permeated after 1 hour $\left(\mathrm{Y}_{3}\right)$. The factor levels and dependent variables of the design are presented in Table 1.

Fifteen experimental runs of the SMV-zein nanoparticle formulation, as depicted in Table 2, were prepared by liquidliquid phase separation method. Sodium caseinate was used as a stabilizer. Briefly, zein and SMV were first dissolved in $10 \mathrm{~mL}$ ethanolic solution $(70 \%-90 \%)$ according to the experimental design (Table 2). The drug-polymer-ethanol solution was rapidly poured into $18 \mathrm{~mL}$ of sodium caseinate solution with stirring (2,000 rpm), using an overhead stirrer, for 30 minutes. SMV-zein nanoparticles were spontaneously formed by phase separation. The resultant dispersion was allowed to evaporate the ethanolic content. Then, the final aqueous dispersions were centrifuged and freeze-dried using trehalose as cryoprotectant.

\section{Characterization of the prepared nanoparticles}

\section{Particle size analysis}

The prepared SMV-zein nanoparticles were assayed for mean particle size distribution using a Zetatrac ${ }^{\circledR}$ particle size analyzer (Microtrac Inc., Montgomeryville, PA, USA) after the nanoparticles were well dispersed in ultrapure water. The data were obtained from three replicate samples.

Table I Independent and dependent variables and their levels for Box-Behnken design

\begin{tabular}{|c|c|c|c|c|c|c|c|}
\hline \multirow[t]{2}{*}{ Factors } & \multicolumn{3}{|c|}{ Levels } & \multicolumn{4}{|l|}{ Constraints } \\
\hline & -1 & 0 & $+\mathbf{I}$ & $\begin{array}{l}\text { Dependent } \\
\text { variables }\end{array}$ & Minimum & Maximum & Goal \\
\hline $\bar{x}$ & 10 & 30 & 50 & $Y$ & $134 \mathrm{~nm}$ & $195.3 \mathrm{~nm}$ & $\overline{\text { Minimize }}$ \\
\hline$X_{2}$ & 70 & 80 & 90 & $Y_{2}$ & $55.46 \%$ & $97.05 \%$ & Minimize \\
\hline$x_{3}^{2}$ & 30 & 40 & 50 & $Y_{3}^{2}$ & $15.5 \%$ & $51.3 \%$ & Maximize \\
\hline
\end{tabular}

Notes: Factors studied were percentage of SMV in the SMV-zein mixture $\left(X_{1}\right)$, ethanol concentration $\left(X_{2}\right)$, and caseinate concentration $\left(X_{3}\right)$. The selected dependent variables were mean particle size $\left(\mathrm{Y}_{1}\right)$, SMV encapsulation efficiency $\left(\mathrm{Y}_{2}\right)$, and cumulative percentage of drug permeated after I hour $\left(\mathrm{Y}_{3}\right)$. 
Table 2 Experimental runs and their observed dependent variables

\begin{tabular}{|c|c|c|c|c|c|c|}
\hline \multirow[t]{2}{*}{ Run } & \multicolumn{3}{|c|}{ Factors } & \multicolumn{3}{|c|}{ Dependent variables } \\
\hline & $\mathbf{x}_{1}$ & $\mathbf{x}_{2}$ & $x_{3}$ & $\mathbf{Y}_{1}$ & $\mathbf{Y}_{2}$ & $\mathbf{Y}_{3}$ \\
\hline I & 50 & 90 & 40 & 186 & 66.32 & 18.7 \\
\hline 2 & 50 & 80 & 50 & 195 & 63.65 & 15.5 \\
\hline 3 & 30 & 70 & 50 & 136 & 57.37 & 51.2 \\
\hline 4 & 10 & 70 & 40 & 137 & 89.21 & 44 \\
\hline 5 & 30 & 70 & 30 & 181 & 90.74 & 39 \\
\hline 6 & 30 & 90 & 50 & 183 & 77.35 & 29 \\
\hline 7 & 50 & 80 & 30 & 180 & 55.46 & 32.6 \\
\hline 8 & 10 & 80 & 50 & 155 & 94.7 & 30.7 \\
\hline 9 & 10 & 80 & 30 & 134 & 91.7 & 31 \\
\hline 10 & 50 & 70 & 40 & 190 & 86.38 & 31.3 \\
\hline II & 30 & 90 & 30 & 172 & 79.72 & 20.3 \\
\hline 12 & 10 & 90 & 40 & 156 & 97.05 & 15.6 \\
\hline 13 & 30 & 80 & 40 & 174 & 86.5 & 36.7 \\
\hline 14 & 30 & 80 & 40 & 158 & 82.5 & 34.3 \\
\hline 15 & 30 & 80 & 40 & 162 & 79.9 & 33.3 \\
\hline
\end{tabular}

Notes: Factors studied were percentage of SMV in the SMV-zein mixture $\left(X_{1}\right)$, ethanol concentration $\left(\mathrm{X}_{2}\right)$, and caseinate concentration $\left(\mathrm{X}_{3}\right)$. The selected dependent variables were mean particle size $\left(Y_{1}\right)$, SMV encapsulation efficiency $\left(Y_{2}\right)$, and cumulative percentage of drug permeated after I hour $\left(\mathrm{Y}_{3}\right)$.

\section{Determination of SMV encapsulation efficiency}

The total drug in the prepared nanoparticles was determined by dissolving SMV-zein nanoparticles in $70 \% \mathrm{w} / \mathrm{v}$ ethanol solution. The solution was then filtered through $0.22 \mu \mathrm{m}$ filters and assayed for SMV content by high-performance liquid chromatography (HPLC). ${ }^{23} \mathrm{SMV}$ encapsulation efficiency was determined by Equation 1.

$$
\begin{aligned}
& \text { Encapsulation } \\
& \text { efficiency }(\mathrm{w} / \mathrm{w} \%)
\end{aligned}=\frac{\begin{array}{l}
\text { Amount of SMV in } \\
\text { the nanoparticles }
\end{array}}{\text { Weight of SMV initially added }}
$$

\section{In vitro diffusion study}

The diffusion of SMV from the prepared nanoparticles specified by the design was carried out using an automated Franz diffusion cell apparatus (MicroettePlus ${ }^{\mathrm{TM}}$; Hanson Research, Chatsworth, USA), with $1.76 \mathrm{~cm}^{2}$ of diffusion area and a receptor chamber of $7 \mathrm{~mL}$ volume. Synthetic nylon membrane of $0.45 \mu \mathrm{m}$ pore size (Pall Corp, Port Washington, NY, USA) was used as diffusion membrane. The prepared nanoparticles were placed between the donor and receptor compartments. Phosphate-buffered saline ( $\mathrm{pH} 7.0)$ containing Tween $20(0.5 \% \mathrm{w} / \mathrm{v})$ was used as a diffusion medium in the receptor chamber, stirred at $400 \mathrm{rpm}$. Aliquots withdrawn by the autosampler were analyzed for SMV content by HPLC. Each test was carried out in triplicate.

\section{Examination of nanoparticle morphology}

The morphology of the optimized caseinate-coated SMV-zein nanoparticles was examined by using field emission scanning electron microscopy (SEM) (Jeol JSM-7600f). The SMV-zein nanoparticles were vacuum-dried at room temperature prior to examination under SEM.

In vivo application of optimized SMV-zein nanoparticles Male Wistar rats weighing 200-250 g were used in this study. The animal use was approved by the local Institutional Review Board for Preclinical and Clinical Research, ensuring that the care and use of animals conformed to the European Union (EU) Legislation for the protection of animals used for scientific purposes. ${ }^{24,25}$ The animals were divided into three groups. The first group was orally administered plain zein nanoparticles (negative control). The second group was orally administered SMV suspension (positive control) at a dose of $5 \mathrm{mg} / \mathrm{kg}$ body weight. The third group was orally administered optimized formula of caseinate-coated SMV-zein nanoparticles at the same dose, $5 \mathrm{mg} / \mathrm{kg}$. Pharmacokinetic parameters, namely maximum plasma concentration $\left(\mathrm{C}_{\max }\right)$, time point of maximum plasma concentration, elimination rate constant, half-life, mean absorption time, and area under the plasma concentration-time curve were calculated based on serum SMV concentrations.

\section{Results and discussions}

\section{Formulation and characterization of caseinate-coated SMV-zein nanoparticles}

The growing prevalence of dyslipidemia necessitates various strategies to prevent this problem. Improvement of the efficiency and accuracy of currently used treatments is one of the strategies applied. This study aimed to develop caseinate-coated SMV-zein nanoparticles, to obtain the optimum formula, and to control preparation factors. Table 1 summarizes the experimental runs, their factor combinations, and the levels of each factor used in the study as well as the dependent variable constraints. According to a Box-Behnken experimental design, the factor combinations yielded various values of observed mean dependent variables. The observed dependent variables were $\mathrm{Y}_{1}, \mathrm{Y}_{2}$, and $\mathrm{Y}_{3}$, as shown in Table 2. The results for $\mathrm{Y}_{1}$ were in the range from 134 to $195 \mathrm{~nm}$ for runs 9 and 2, respectively.

Standardized Pareto charts were utilized to identify the significant $(P<0.05)$ studied factors and their interaction on certain dependent variables as shown in Figure 1. A positive sign illustrated a direct relationship of the variable with the dependent variable. On the other hand, a negative sign showed inverse relationship. The data showed a range for $\mathrm{Y}_{2}$ from $55.46 \%$ (run 7) to $97.05 \%$ (run 12). In the case of $\mathrm{Y}_{3}$, results were in the range of $15.5 \%$ to $51.2 \%$ for run 2 and 3, respectively. The $P$-values resulted from analysis of variance (ANOVA) and were 0.006, 0.016, and 0.006 for 

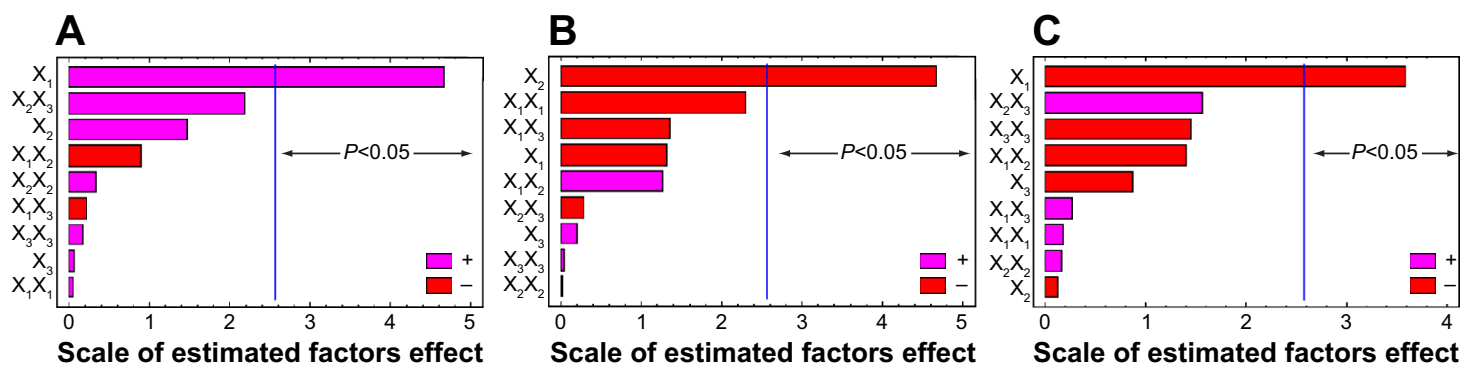

Figure I Standard Pareto charts showing the effects of independent variables and their combined effects on particle size (A), SMV EE (B), and cumulative amount permeated after I hour (C).

Note: Factors studied were percentage of SMV in the SMV-zein mixture $\left(X_{1}\right)$, ethanol concentration $\left(X_{2}\right)$, and caseinate concentration $\left(X_{3}\right)$. +, positive effect of the factor; - , negative effect of the factor.

Abbreviations: $\mathrm{EE}$, encapsulation efficiency; SMV, simvastatin.

the dependent variables $\mathrm{Y}_{1}, \mathrm{Y}_{2}$ and $\mathrm{Y}_{3}$, respectively. These results indicated a significant effect of the independent factors $\left(\mathrm{X}_{1}\right.$ and $\left.\mathrm{X}_{2}\right)$ on the dependent variables as shown in Table 3. On the other hand, $X_{3}$ was nonsignificant for its influences on the investigated dependent variables. Caseinate concentration, expressed as $\mathrm{X}_{3}$, was a significant factor for the critical characteristics of the prepared nanoparticles during the preliminary screening design experiments (data not shown). The screening study was performed according to Plackett Burmann design, as a component of a seven factor design. This variable was significant for its effects on the volume weighted particle size and size distribution and the resultant zeta potential. However, it was nonsignificant for drug content and release attributes. Hence, it was included in the current optimization study for its effect on particle size. Unfortunately, the experiments factorial combinations showed the nonsignificant effect of $X_{3}$ on the investigated dependent variables. This demonstrates the importance of the risk analysis before attempting to optimize the formulation.

The interaction of the factors and their quantitative effects on the dependent variables were generated in mathematical regression Equations 1, 2, and 3, for the observed dependent variables $Y_{1}, Y_{2}$ and $Y_{3}$, respectively. Theoretical values of the dependent variables, and $Y_{1}, Y_{2}$, and $\mathrm{Y}_{3}$ were obtained by the substitution of $\mathrm{X}_{1}-\mathrm{X}_{3}$ values in Equations 2, 3, and 4.

$$
\begin{aligned}
\mathrm{Y}_{1}= & 611.497+3.593 \mathrm{X}_{1}-7.681 \mathrm{X}_{2}-11.820 \mathrm{X}_{3} \\
& +0.001 \mathrm{X}_{1}^{2}-0.029 \mathrm{X}_{1} \mathrm{X}_{2}-0.007 \mathrm{X}_{1} \mathrm{X}_{3} \\
& +0.0225417 \mathrm{X}_{2}^{2}+0.14 \mathrm{X}_{2} \mathrm{X}_{3}+0.011 \mathrm{X}_{3}^{2} \\
\mathrm{Y}_{2}= & 225.417+1.761 \mathrm{X}_{1}-3.447 \mathrm{X}_{2}-0.688 \mathrm{X}_{3} \\
& +0.002 \mathrm{X}_{1}^{2}-0.035 \mathrm{X}_{1} \mathrm{X}_{2}+0.006 \mathrm{X}_{1} \mathrm{X}_{3} \\
& +0.008 \mathrm{X}_{2}^{2}+0.077 \mathrm{X}_{2} \mathrm{X}_{3}-0.075 \mathrm{X}_{3}^{2} \\
\mathrm{Y}_{3}= & 100.181+0.226 \mathrm{X}_{1}-1.324 \mathrm{X}_{2}+1.322 \mathrm{X}_{3} \\
& +0.0185 \mathrm{X}_{1}^{2}+0.0198 \mathrm{X}_{1} \mathrm{X}_{2}-0.021 \mathrm{X}_{1} \mathrm{X}_{3} \\
& +0.0004 \mathrm{X}_{2}^{2}+0.009 \mathrm{X}_{2} \mathrm{X}_{3}+0.001 \mathrm{X}_{3}^{2}
\end{aligned}
$$

\begin{tabular}{|c|c|c|c|c|c|c|}
\hline \multirow[t]{3}{*}{ Factor } & \multicolumn{6}{|c|}{ Dependent variables } \\
\hline & \multicolumn{2}{|l|}{$\mathbf{Y}_{1}$} & \multicolumn{2}{|l|}{$\mathbf{Y}_{2}$} & \multicolumn{2}{|l|}{$\mathbf{Y}_{3}$} \\
\hline & Estimated effect & $P$-value & Estimated effect & $P$-value & Estimated effect & $P$-value \\
\hline$x_{1}$ & 42.325 & $0.006^{*}$ & -25.213 & $0.016 *$ & -5.8 & 0.243 \\
\hline$x_{2}$ & 13.25 & 0.204 & -0.815 & 0.912 & -20.5 & $0.006 *$ \\
\hline$x_{3}^{2}$ & 0.575 & 0.952 & -6.138 & 0.423 & 0.9 & 0.846 \\
\hline$x_{1}^{3}$ & 0.658 & 0.963 & 1.856 & 0.865 & -14.817 & 0.070 \\
\hline$x_{1} x_{2}$ & -11.5 & $0.4 I I$ & -13.95 & 0.220 & 7.9 & 0.259 \\
\hline$x_{1} x_{3}^{2}$ & -2.85 & 0.833 & 2.595 & 0.805 & -8.4 & 0.234 \\
\hline$x_{2}^{2}$ & 4.508 & 0.75 & 1.691 & 0.877 & 0.0833 & 0.990 \\
\hline$x_{2}^{2} x_{3}$ & 28 & 0.081 & 15.5 & 0.18 & -1.8 & 0.783 \\
\hline$x_{3}^{2}$ & 2.158 & 0.878 & -15.034 & 0.207 & 0.1833 & 0.978 \\
\hline
\end{tabular}

The dependent variable $Y_{3}$, cumulative percentage of drug permeated after 1 hour, was selected as a result of

Table 3 Estimated effects and associated $P$-values for all three dependent variables

Notes: *Significant $(P<0.05)$ effect of factors on individual dependent variables. Factors studied were percentage of SMV in the SMV-zein mixture $\left(X_{1}\right)$, ethanol concentration $\left(X_{2}\right)$, and caseinate concentration $\left(X_{3}\right)$. The selected dependent variables were mean particle size $\left(Y_{1}\right)$, SMV encapsulation efficiency $\left(Y_{2}\right)$, and cumulative percentage of drug permeated after I hour $\left(\mathrm{Y}_{3}\right)$. 
the sustained release nature of the formulated SMV-zein nanoparticles. The initial release (burst effect) of sustainedrelease formulations can be viewed in two perspectives, either as negative or desirable consequence, according to the detailed review by Huang and Brazel. ${ }^{26}$ In case of the SMVzein nanoparticles, because of the hydrophobic nature of both SMV (drug) and zein (polymer), it is desirable to obtain high initial rates of delivery to initiate SMV therapy.

The response surface and contours of the estimated response surface plots (Figure 2) reveal the dependent and independent variable relationships. The optimized caseinatecoated SMV-zein nanoparticle formula was prepared according to the predicted $X_{1}, X_{2}$, and $X_{3}$ levels, to measure the obtained dependent variables and for comparison with the calculated values. The observed, predicted values and the residuals for the optimized formula are shown in Table 4.

The GIT absorption efficiency of nanoparticles is strongly affected by the particle size. Larger particles (about $500 \mathrm{~nm}$ in size) can be taken by phagocytic-uptake, while for the smaller size nanoparticles, the main route of entry is through fluid phase endocytosis. ${ }^{27,28}$ The external structural properties of the optimized formula were characterized by SEM technique. SEM image (Figure 3) of the optimized formula showed spherical particles, with uniform size distribution. The mean particle size was $131 \mathrm{~nm}$, as measured by the nanosizer described in the "Materials and methods". SMV nanoparticles were discrete entities and compactly arranged, as a result of the process of centrifugation, and without
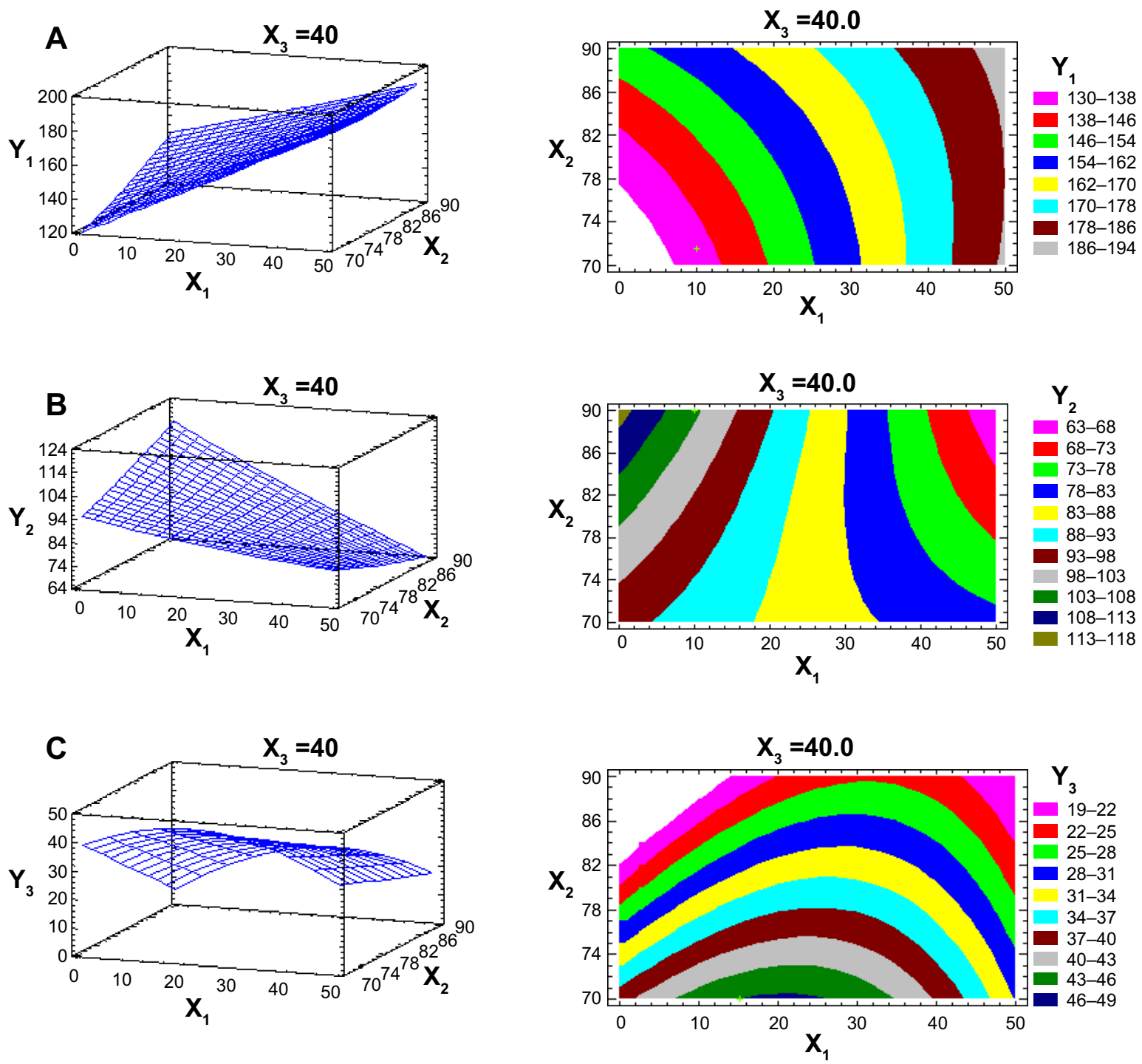

Figure 2 The effects of independent variables and their combined effects on $Y_{1}, Y_{2}$, and $Y_{3}$, represented as three-dimensional (3D) response surface plots (left side) and contours of estimated response surface plots (right side).

Notes: Factors studied were percentage of SMV in the SMV-zein mixture $\left(X_{1}\right)$, ethanol concentration $\left(X_{2}\right)$, and caseinate concentration $\left(X_{3}\right)$. The selected dependent variables were mean particle size $\left(\mathrm{Y}_{1}\right)$, SMV encapsulation efficiency $\left(\mathrm{Y}_{2}\right)$, and cumulative percentage of drug permeated after I hour $\left(\mathrm{Y}_{3}\right)$. 
Table 4 Predicted, observed values and the residuals for the optimized SMV-zein nanoparticles

\begin{tabular}{llllll}
\hline \multicolumn{4}{l}{ Optimized formulation } \\
\hline Factors & Level & $\begin{array}{l}\text { Dependent } \\
\text { variables }\end{array}$ & Predicted & Observed & Residuals \\
\hline$X_{1}$ & $10.0005 \%$ & $Y_{1}$ & 134.0 & 131.4 & 2.6 \\
$X_{2}$ & $70 \%$ & $Y_{2}$ & 91.057 & 89.21 & 1.847 \\
$X_{3}$ & $39.767 \%$ & $Y_{3}$ & 44.371 & 42.20 & 2.171 \\
\hline
\end{tabular}

Abbreviation: SMV, simvastatin.

Notes: Factors studied were percentage of SMV in the SMV-zein mixture $\left(X_{1}\right)$, ethanol concentration $\left(X_{2}\right)$, and caseinate concentration $\left(X_{3}\right)$. The selected dependent variables were mean particle size $\left(Y_{1}\right)$, SMV encapsulation efficiency $\left(Y_{2}\right)$, and cumulative percentage of drug permeated after I hour $\left(\mathrm{Y}_{3}\right)$.

evidence of collapsed spheres, which may reveal good complete removal of solvent from the nanoparticles. ${ }^{29}$

\section{In vitro membrane permeation of optimized nanoparticles}

Figure 4 depicts the percentage of SMV permeated from the optimized caseinate-coated SMV-zein nanoparticles. Results revealed a biphasic sustained-release pattern during the 48-hour release study. The initial (burst effect) stage is usually attributed to the fast release of drug entrapped near the surface of the nanoparticles. After the initial stage, SMV release was characterized by a slow-release stage. After 12 hours, about $43 \%$ of SMV in zein nanoparticles was released. About $85 \%$ of the entrapped SMV was released after 48 hours.

The slow release pattern of SMV from nanoparticles after the initial stage could be attributed to deeper entrapped SMV in the core matrix of zein nanoparticles. SMV in the core of the nanoparticles has a longer diffusion path to reach the surface compared with SMV entrapped near the surface. ${ }^{14}$ The release of SMV from the core matrix zein nanoparticles

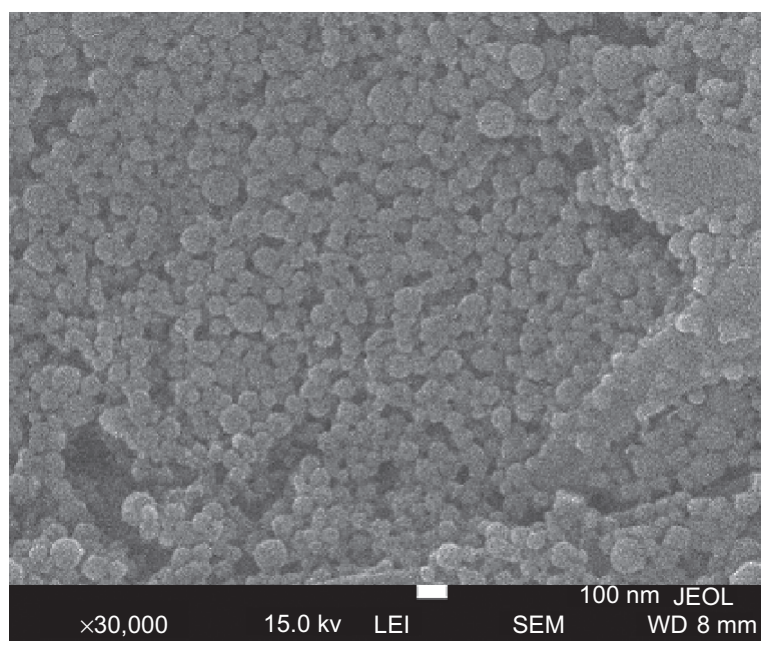

Figure 3 SEM image of optimized caseinate-coated SMV-zein nanoparticles. Abbreviations: SEM, scanning electron microscopy; SMV, simvastatin.

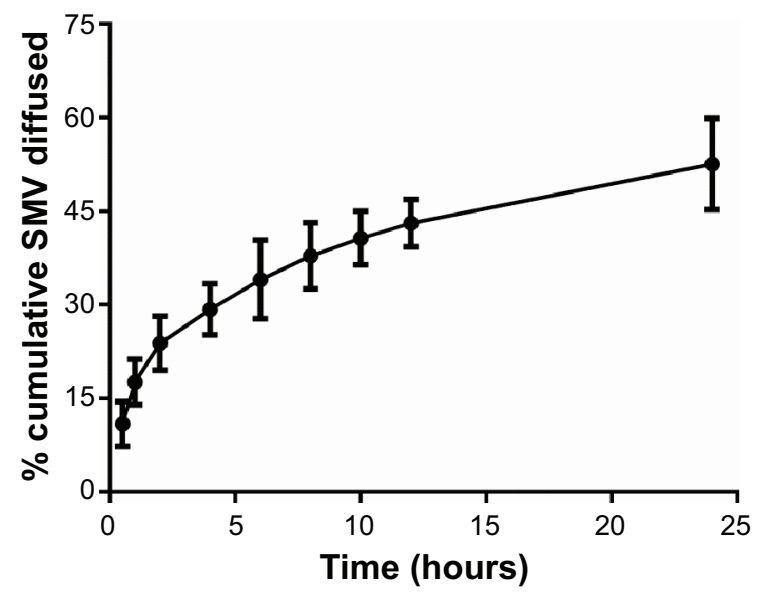

Figure 4 In vitro permeation of optimized SMV-zein nanoparticles. Abbreviation: SMV, simvastatin.

is controlled by the parameters affecting drug-release kinetics from the polymeric matrix. These parameters are: drug dissolution/diffusion rate, the rate of water uptake, and the size of the particles and their matrix erosion/degradation rate. ${ }^{30-33} \mathrm{In}$ addition, the hydrophobic nature of zein augments the delay of water penetration and could retard the diffusion of the poorly water soluble SMV into the release medium. On the other hand, SMV zein nanoparticles release showed improved release characteristics compared with previously reported zein microspheres containing the poorly water soluble drug ivermectin, as a result of the increased ratio of surface area-to-particle volume. ${ }^{14}$

\section{In vivo application of optimized SMV-zein nanoparticles}

The pharmacokinetic study of the optimized SMV-zein nanoparticles showed lower initial plasma concentration relative to oral suspension for the first 2 hours, possibly because SMV was released slowly from the caseinate-coated zein nanoparticles for an extended period of time. After 2 hours, the plasma concentration of SMV released from the nanoparticles began to rise in relation to oral suspension. The optimized SMVzein showed a higher $\mathrm{C}_{\max }$ and a relatively higher area under plasma-time curve compared with SMV suspension, as shown in Figure 5. The $\mathrm{C}_{\max }$ of SMV was 23.57 and $14.52 \mu \mathrm{g} / \mathrm{L}$ for the optimized SMV-zein nanoparticles and SMV suspension, respectively (Figure 5). The results also revealed that the nanoparticles could significantly modify the pharmacokinetic profile and can increase the bioavailability of SMV by more than fourfold in comparison with the oral suspension.

These results indicated that formulation of SMV as caseinate-coated zein nanoparticles formulation enhanced its dissolution and absorption characteristics across the GIT 


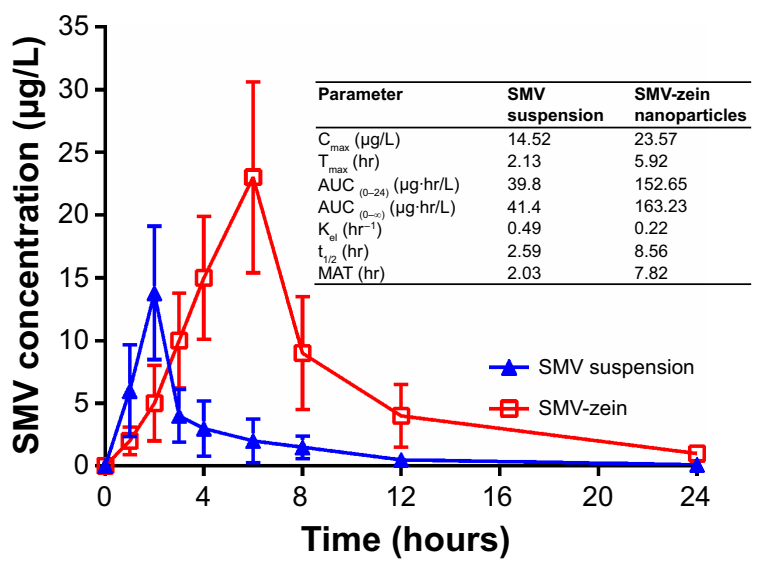

Figure 5 Means of plasma concentrations-time profiles and in vivo pharmacokinetic parameters (Inset) of optimized SMV-zein nanoparticles and SMV suspension. Abbreviations: $A \cup C$, area under the time-concentration curve; $C_{\max }$, maximum plasma concentration; $K_{e l}$, elimination rate constant; $M R T$, mean residence time; SMV, simvastatin; $t_{1 / 2}$, half-life; $T_{\max }$, time to reach $C_{\max }$.

membrane. This could be attributed to the fact that preparation of SMV, a poorly water soluble drug, as nanoparticles formulation enhanced, not only solubility of SMV but also, tissue permeability and GIT paracellular absorption of the nanoparticles. Also, the nanoparticles were introducing a drug as fine dispersion compared with coarse particles in the case of oral suspension, and hence, an increased surface area with reduced diffusion path length. ${ }^{34}$ In addition, the presence of caseinate as a coating for SMV-zein nanoparticles provided a higher adhesion surface contact between nanoparticles and the absorption site, which enhanced the permeation of SMV through the GIT membrane. These results showed that a distinct advantage of nanoparticle formulation might be to improve SMV performance and bioavailability in vivo.

\section{Conclusion}

The formulation of systematically optimized caseinate-coated SMV-zein nanoparticles significantly improved the pharmacokinetic profile and bioavailability of SMV by more than fourfold in comparison with SMV oral suspension. These results indicate that formulation of SMV as caseinate-coated zein nanoparticles enhanced the dissolution characters and sustained the release of SMV. As a result, hypolipidemic activities could be improved for longer time and with lower dosing frequency, which could improve patient tolerability and compliance.

\section{Acknowledgment}

This project was funded by the Deanship of Scientific Research (DSR), King Abdulaziz University, Jeddah (grant number 318/166/1434). The authors therefore acknowledge, with thanks, DSR technical and financial support. The authors would like to thank Dr KM El-Say (Faculty of Pharmacy, King Abdulaziz University) for useful discussions of the experimental design.

\section{Disclosure}

The authors report no conflicts of interest in this work.

\section{References}

1. Mishra S, Panda DS, Pradhan M, Hussain I. Preparation and evaluation of ezetimibe nanosuspension. Journal of Advanced Pharmaceutical Research. 2011;2:185-189.

2. von Briesen H, Ramge P, Kreuter J. Controlled release of antiretroviral drugs. AIDS Rev. 2000;2:31-38.

3. Baigent C, Keech A, Kearney PM, et al; Cholesterol Treatment Trialists' (CTT) Collaborators. Efficacy and safety of cholesterollowering treatment: prospective meta-analysis of data from 90,056 participants in 14 randomised trials of statins. Lancet. 2005;366(9493): $1267-1278$.

4. Cannon CP, Steinberg BA, Murphy SA, Mega JL, Braunwald E. Metaanalysis of cardiovascular outcomes trials comparing intensive versus moderate statin therapy. J Am Coll Cardiol. 2006;48(3):438-445.

5. Costa J, Borges M, David C, Vaz Carneiro A. Efficacy of lipid lowering drug treatment for diabetic and non-diabetic patients: meta-analysis of randomised controlled trials. BMJ. 2006;332(7550):1115-1124.

6. Joukhadar C, Klein N, Prinz M, et al. Similar effects of atorvastatin, simvastatin and pravastatin on thrombogenic and inflammatory parameters in patients with hypercholesterolemia. Thromb Haemost. 2001; 85(1):47-51.

7. Sparrow CP, Burton CA, Hernandez M, et al. Simvastatin has anti-inflammatory and antiatherosclerotic activities independent of plasma cholesterol lowering. Arterioscler Thromb Vasc Biol. 2001; 21(1):115-121.

8. Sav AK, Ali MT, Fule RA, Amin PD. Formulation of highly purified fenugreek gum based silica lipid drug delivery system for simvastatin with enhanced dissolution rate and in vitro characterization. Journal of Pharmaceutical Investigation. 2013;43:363-373.

9. El-Say KM, Ahmed TA, Badr-Eldin SM, Fahmy U, Aldawsari H, Ahmed OA. Enhanced permeation parameters of optimized nanostructured simvastatin transdermal films: ex vivo and in vivo evaluation. Pharm Dev Technol. Epub 2014 Jul 14.

10. Constantinides PP. Lipid microemulsions for improving drug dissolution and oral absorption: physical and biopharmaceutical aspects. Pharm Res. 1995;12(11):1561-1572.

11. Arias JL, López-Viota M, Gallardo V, Adolfina Ruiz M. Chitosan nanoparticles as a new delivery system for the chemotherapy agent tegafur. Drug Dev Ind Pharm. 2010;36(6):744-750.

12. Ahmed TA, El-Say KM. Development of alginate-reinforced chitosan nanoparticles utilizing W/O nanoemulsification/internal crosslinking technique for transdermal delivery of rabeprazole. Life Sci. 2014; 110(1):35-43.

13. Sonaje K, Italia JL, Sharma G, Bhardwaj V, Tikoo K, Kumar MN. Development of biodegradable nanoparticles for oral delivery of ellagic acid and evaluation of their antioxidant efficacy against cyclosporine A-induced nephrotoxicity in rats. Pharm Res. 2007;24(5):899-908.

14. Liu X, Sun Q, Wang H, Zhang L, Wang JY. Microspheres of corn protein, zein, for an ivermectin drug delivery system. Biomaterials. 2005;26(1):109-115.

15. Shukla R, Cheryan M. Zein: the industrial protein from corn. Industrial Crops and Products. 2001;13(3):171-192.

16. Önal U, Langdon C. Performance of zein-bound particles for delivery of riboflavin to early fish larvae. Aquaculture Nutrition. 2005;11: $351-358$. 
17. Demchak RJ, Dybas RA. Photostability of abamectin/zein microspheres. J Agric Food Chem. 1997;45(1):260-262.

18. Patel A, Hu Y, Tiwai JK, Velikov KP. Synthesis and characterisation of zein-curcumin colloidal particles. Soft Matter. 2010;6:6192-6199.

19. Zhong Q, Jin M. Nanoscalar structures of spray-dried zein microcapsules and in vitro release kinetics of the encapsulated lysozyme as affected by formulations. J Agric Food Chem. 2009;57(9):3886-3894.

20. Patel AR, Bouwens EC, Velikov KP. Sodium caseinate stabilized zein colloidal particles. J Agric Food Chem. 2010;58(23):12497-12503.

21. Park YW, Juárez M, Ramos M, Haenlein GFW. Physico-chemical characteristics of goat and sheep milk. Small Rumint Res. 2007;68:88-113.

22. Korhonen H. Milk-derived bioactive peptides: From science to applications. J Funct Foods. 2009;1(2):177-187.

23. Dixit RP, Barhate CR, Padhye SG, Viswanathan CL, Nagarsenker MS. Stability indicating RP-HPLC method for simultaneous determination of simvastatin and ezetimibe from tablet dosage form. Indian J Pharm Sci. 2010;72(2):204-210.

24. Legislation for the protection of animals used for scientific purposes [webpage on the Internet. Belgium: European Commission; 2014. Available from: http://ec.europa.eu/environment/chemicals/lab_animals/ legislation_en.htm. Accessed December 15, 2014.

25. Guiding Principles for the Care and Use of Vertebrate Animals in Research and Training [webpage on the Internet]. Bethesda: American Phsiological Society; 2014. Available from: http://www.the-aps.org/ $\mathrm{mm} /$ SciencePolicy/About/Policy-Statements/Guiding-Principles.html. Accessed December 15, 2014.

26. Huang X, Brazel CS. On the importance and mechanisms of burst release in matrix-controlled drug delivery systems. $J$ Control Release. 2001;73(2-3):121-136.
27. Panariti A, Miserocchi G, Rivolta I. The effect of nanoparticle uptake on cellular behavior: disrupting or enabling functions? Nanotechnol Sci Appl. 2012;5:87-100.

28. Dong Y, Feng SS. Poly(d,1-lactide-co-glycolide)/montmorillonite nanoparticles for oral delivery of anticancer drugs. Biomaterials. 2005;26(30):6068-6076.

29. Ahlin P, Kristl J, Kristl A, Vrecer F. Investigation of polymeric nanoparticles as carriers of enalaprilat for oral administration. Int J Pharm. 2002;239(1-2):113-120.

30. Berkland C, Kim K, Pack DW. Fabrication of PLG microspheres with precisely controlled and monodisperse size distributions. J Control Release. 2001;73(1):59-74.

31. Brazel CS, Peppas NA. Modeling of drug release from swellable polymers. Eur J Pharm Biopharm. 2000;49(1):47-58.

32. Franssen O, Stenekes RJ, Hennink WE. Controlled release of a model protein from enzymatically degrading dextran microspheres. J Control Release. 1999;59(2):219-228.

33. Oneda F, Re MI. The effect of formulation variables on the dissolution and physical properties of spray-dried microspheres containing organic salts. Powder Technology. 2003;130(1-3):377-384.

34. Hosny KM, Aljaeid BM. Sildenafil citrate as oral solid lipid nanoparticles: a novel formula with higher bioavailability and sustained action for treatment of erectile dysfunction. Expert Opin Drug Deliv. 2014;11(7):1015-1022.
Drug Design, Development and Therapy

\section{Publish your work in this journal}

Drug Design, Development and Therapy is an international, peerreviewed open-access journal that spans the spectrum of drug design and development through to clinical applications. Clinical outcomes, patient safety, and programs for the development and effective, safe, and sustained use of medicines are a feature of the journal, which

\section{Dovepress}

has also been accepted for indexing on PubMed Central. The manuscript management system is completely online and includes a very quick and fair peer-review system, which is all easy to use. Visit http://www.dovepress.com/testimonials.php to read real quotes from published authors.

Submit your manuscript here: http://www.dovepress.com/drug-design-development-and-therapy-journal 